\title{
Peculiarities of hydration of Portland cement with synthetic nano-silica
}

\author{
Galyna Kotsay \\ Warsaw University of Technology, Branch at Płock, Poland \\ e-mail: galyna.kotsay@pw.edu.pl
}

\begin{abstract}
Application of nano-materials in cement products significantly, improves their properties. Of course, the effectiveness of the materials depends on their quantity and the way they are introduced into the system. So far, amongst nano-materials used in construction, the most preferred was nano-silica. This research investigated the effect of synthetic precipitated nano-silica on the cement hydration as well as, on the physical and mechanical properties of pastes and mortars. Obtained results showed that admixture of nano-silica enhanced flexural and compressive strength of cement after 2 and 28 days, however, only when admixture made up $0.5 \%$ and $1.0 \%$. On the other hand, the use of nano-silica in the amount $2 \%$ had some limitations, due to its ability to agglomerate, which resulted in deterioration of the rheological and mechanical properties.
\end{abstract}

Key words: nano-silica, Portland cement, hydration, calorimetric, paste, mortar, setting time, rate evolution of heat, flexural and compressive strength

\section{Introduction}

In the modern technology of building materials' production, materials are modified with nanoparticles or nano-composites $[1,2,3]$. Those materials have shown increased activity, what significantly have improved their properties and gave the opportunity to create new ones. It was considered that the modification of construction products with nano-materials has increased cohesiveness of the whole system because of its greater adhesion and cohesion [4]. However, using nano-particles can cause some problems such as their homogenization in the system and, due to high surface energy, the ability to form agglomerates. Therefore, the possibility of using nano-materials is the subject of many research papers [5-10]. Among nano-materials used in construction: nano- $\mathrm{Al}_{2} \mathrm{O}_{3}, \mathrm{TiO}_{2}, \mathrm{Fe}_{2} \mathrm{O}_{3}$ and $\mathrm{SiO}_{2}$, the most preferred is nano-silica, which one, due to its tetrahedral structure, exhibits ease of forming nanocomposites, while on the other hand, the amorphous phase of $\mathrm{SiO}_{2}$ in cementations materials is also, an active pozzolanic admixture. Depending on the method of production, grains can reach size from 5 to $100 \mathrm{~nm}$ with a specific surface varied from 120 to $450 \mathrm{~m}^{2} / \mathrm{g}$, which results in a high water requirement of the paste and hence, deterioration of its properties. The purpose of this paper is to present results of research on impact of applying precipitating nano-silica as an admixture on hydration process of cement, as well as on physical and mechanical properties of pastes and mortars. 


\section{Materials and investigation methods}

For this research purposes, Portland Cement CEM I 32.5 R and synthetic precipitated nanosilica (NS) with pozzolanic activity of $405 \mathrm{mg} \mathrm{CaO} / 1 \mathrm{~g}$ [11] were used. Silica was added to pastes and mortars in the amount of $0.5 \%, 1 \%$ and $2 \%$ of the weight of the cement. The chemical composition and specific area of the materials is given in Table 1.

Table 1: Chemical composition and specific area of cement and nano-silica

\begin{tabular}{|c|c|c|c|c|c|c|c|c|c|c|}
\hline \multirow{2}{*}{ Materials } & \multicolumn{8}{|c|}{ Oxides, $\%$ by mass } & \multirow{2}{*}{$\begin{array}{c}\text { Loss of } \\
\text { ignition, } \\
\%\end{array}$} & \multirow{2}{*}{$\begin{array}{c}\text { Specific } \\
\text { area } \\
\left(\mathrm{m}^{2} / \mathrm{g}\right)\end{array}$} \\
\hline & $\mathrm{CaO}$ & $\mathrm{SiO}_{2}$ & $\mathrm{Al}_{2} \mathrm{O}_{3}$ & $\mathrm{Fe}_{2} \mathrm{O}_{3}$ & $\mathrm{MgO}$ & $\mathrm{SO}_{3}$ & $\mathrm{Na}_{2} \mathrm{O}$ & $\mathrm{Cl}^{-}$ & & \\
\hline Cement & & & & & & 3,17 & 0,78 & 0,08 & 2,95 & 0,33 \\
\hline $\begin{array}{c}\text { Nano- } \\
\text { silica (NS) }\end{array}$ & - & $\begin{array}{c}93,5 \\
2\end{array}$ & - & - & - & 0,39 & 0,31 & - & 4,86 & 173 \\
\hline
\end{tabular}

Calorimetric tests were used to determine the effect of synthetic silica on hydration of cement. Cement pastes for research purposes were prepared with a constant water to binder ratio $=$ 0.3. The cement bonding times examination was carried out in accordance with PN-EN 196-3 [12]. The grip between pastes and glass surface was tested after 2, 4, 6, 8, 24 hours of hydration. Test for bond strength of mortar was performed after 2, 28, 90 days according to PN-EN 196-1 [13]. To prepare cement mortars, 1\% of plasticiser, the one based on polycarboxylate ethers, was added. Comparison of the results of strength tests between mortars with synthetic silica and those without any admixture was expressed by the index of active strength $(\mathrm{IAS}=[\mathrm{f} \bmod / \mathrm{fk}] * 100, \%)$.

\section{Results and Discussion}

For this research purposes, synthetic precipitated nano-silica was used, because it exhibits double effects on the properties of the cement paste. On one hand, it adsorbs water, due to a very well-developed specific surface area of $173 \mathrm{~m}^{2} / \mathrm{g}$, which results in elongation of the bonding. On the other hand, it is a very reactive admixture and accelerates the bonding. Adding $1 \%$ of synthetic silica increased the water requirement of the paste by $5.6 \%$, and had pozzolanic reactivity two times stronger than, for example, the micro-silica according to [11].

Calorimetric tests were performed to investigate the effect of different synthetic nano-silica content on cement hydration rates. The results are shown in Fig. 1 and the calorimetric curve characteristics is presented in Table 2 .

Table 2: Characteristic calorimetric of hydration Portland cement with admixtures nano-silica

\begin{tabular}{|c|l|c|c|}
\hline Admixture, \% & $\begin{array}{l}\text { Total heat, } \\
\mathrm{kJ} / \mathrm{kg}\end{array}$ & $\begin{array}{l}\text { Maximum rate evolution of } \\
\text { hate in pre-induction stage of } \\
\text { hydration }(0-0,2 \mathrm{~h}), \mathrm{J} / \mathrm{g} * \mathrm{~h}\end{array}$ \\
\hline 0 & 222,42 & 63,02 & $\begin{array}{l}\text { Maximum rate evolution of } \\
\text { hate in post-induction stage of } \\
\text { hydration }(2-10 \mathrm{~h}), \mathrm{J} / \mathrm{g} * \mathrm{~h}\end{array}$ \\
\hline 0,5 & 242,89 & 31,50 & 8,35 \\
\hline 1 & 221,37 & 31,85 & 8,73 \\
\hline 2 & 220,98 & 50,20 & 8,88 \\
\hline
\end{tabular}



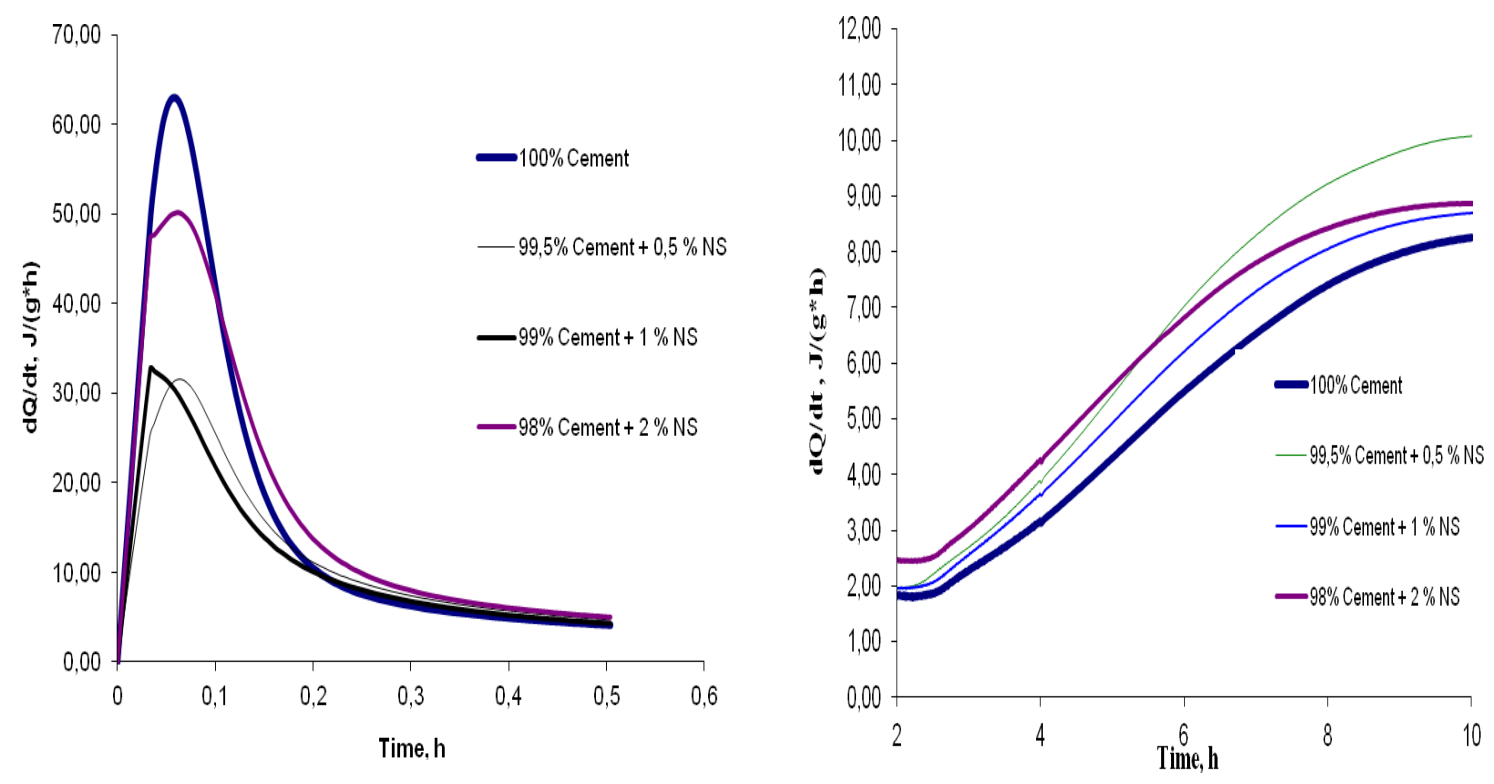

Figure 1: Calorimetric curves hydration of Portland cement with admixtures nano-silica

According to the calorimetric results given in Table 2, the highest hydration heat values were reached after 48 hours of hardening for paste with $0.5 \%$ of synthetic silica. Comparing to the control sample, the heat increased by $9 \%$, indicating the acceleration of cement hydration. While, increasing the amount of admixture up to $1 \%$ and $2 \%$ caused slight reduction in the cement hydration heat.

In the pre-induction stage of cement hydration, the highest heat release rate has been seen in the control cement sample, while introduction of $0.5 \%$ and $1 \%$ of the nano-silica decreased hydration rate almost twice. Reduction of hydration rate was related to water adsorption through nano-silica. On the other hand, increasing the nano-silica content to $2 \%$ has reduced the hydration rate only by $20 \%$, which probably, has been related to the formation of agglomerates. In post-induction period, changes in the hydration rate have been noticed and maximal hydration rate was observed in paste with $0.5 \%$ of nano-silica.

The effect of nano-silica on the bonding time has been presented in Table 3.

Table 3: Setting time of cement pastes with nano-silica (NS)

\begin{tabular}{|c|c|c|}
\hline Binder & Initial setting time, min & Setting time, min \\
\hline $100 \%$ cement & 280 & 60 \\
\hline $99,5 \%$ cement $+0,5 \%$ NS & 275 & 45 \\
\hline $99 \%$ cement $+1 \%$ NS & 250 & 50 \\
\hline $98 \%$ cement $+2 \%$ NS & 180 & 70 \\
\hline
\end{tabular}

Compared to the control sample, the introduction of nano-silica hastened initial setting time for cement paste with $1 \%$ of nano-silica to 30 minutes and to 100 minutes for paste with $2 \%$ of nano-silica. The setting times of paste with $0.5 \%$ and $1 \%$ of nano-silica were shorter by 15 and 10 minutes respectively, when compared to the control sample, while for the paste with $2 \%$ of nano-silica, the setting time was to 20 minutes longer, due to increased water absorption. 
It is known that the mechanical strength of mortar and concrete depends not only on the properties of the paste and aggregate but also, on the bonding force between them. The transition zone between aggregate and paste is characterized by greater porosity, so, it exhibits the weakest strength within the whole concrete. For this reason, the effect of nano-silica on the bonding of the paste to the ideal surface - glass - was determined, see Fig. 2.

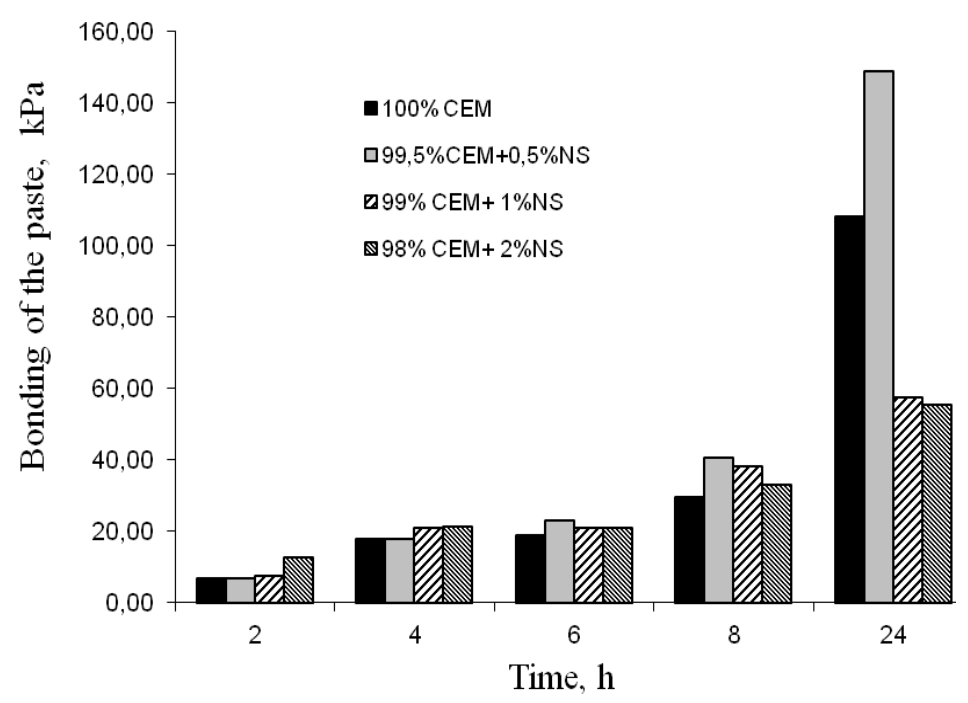

Figure 2: Bonding of the paste after 2, 4, 6, 8, 24 h hydration

Because of high reactivity and water adsorption capacity, the strongest bonding after 2 hours was observed for paste with $2 \%$ of nano-silica. However, after 6 hours, changes in the grip occurred and better results were noticed for paste with $0.5 \%$ of silica. It has been confirmed by calorimetric tests where higher hydration rate was a characteristic for paste with $0.5 \%$ of silica, refer to Fig. 1.
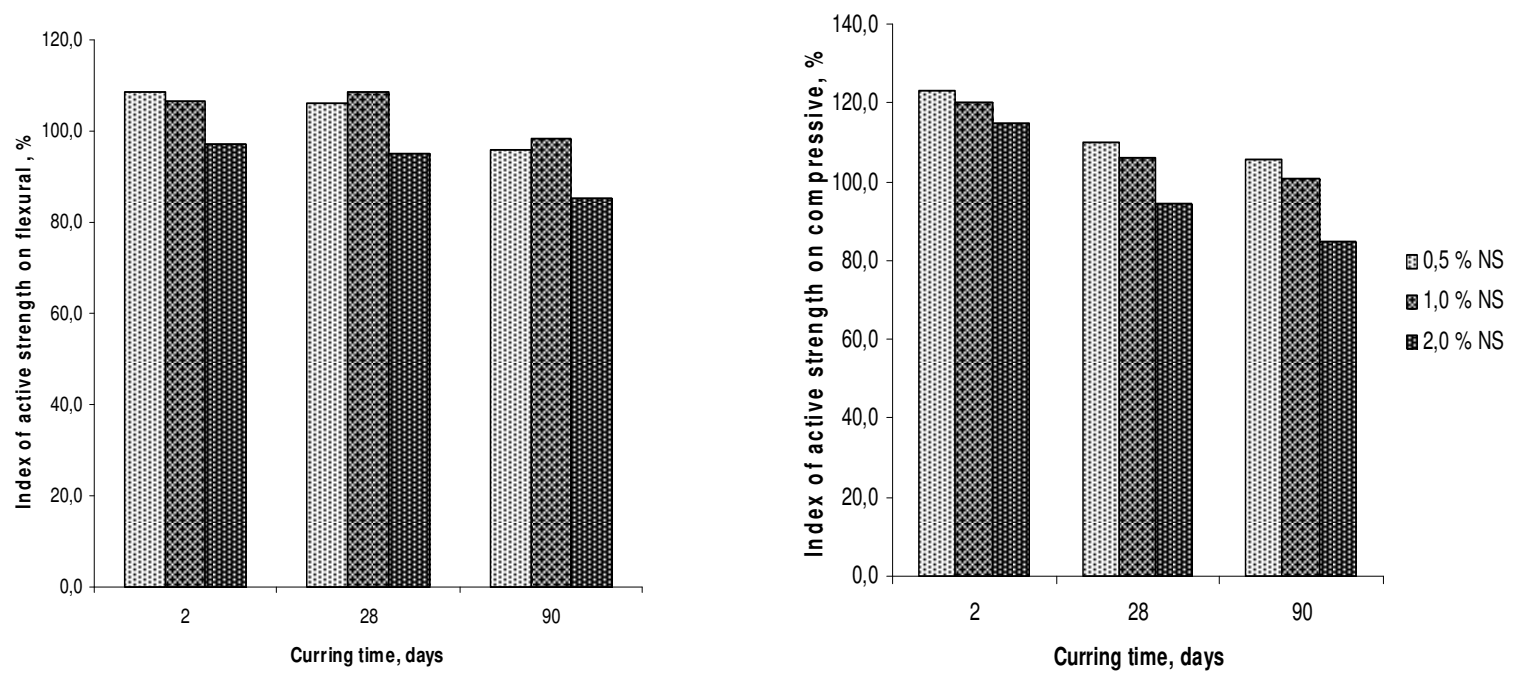

Figure 3: Index of active strength on flexural and compressive vs content of nano-silica after $2,28,90$ days 
The grip of paste with $0.5 \%$ of silica, after 8 and 24 hours of hardening, turned out to be approximately $37 \%$ stronger than the one of the control paste sample. On the other hand, increasing the amount of nano-silica to $1 \%$ and later on, to $2 \%$ has resulted in weaker bond to the surface. After 24 hours of hardening, the grip for investigated paste has decreased twice. In order to determine the effect of nano-silica on flexural and compressive strength, tests were performed after 2, 28 and 90 days, and they were compared to control mortar (IAS, \%).

Studies showed that the addition of $0,5 \%$ and $1 \%$ of nano-silica positively, affected flexural and compressive strengths. Highest IAS results were achieved after 2 days of hydration. Incorporation of $0.5 \%$ of precipitated silica increased early flexural strength by $9 \%$ and compressive strength by $23 \%$. On the other hand, higher amounts of $2 \%$ nano-silica reduced flexural and compressive strength and, after 90 days of hardening, the reduction was up to $15 \%$.

\section{Conclusion}

Choosing the right amount of nano-silica has been crucial for the rheological properties of cement paste and mechanical properties of mortars. The results of conducted research showed that the admixture of nano-silica positively, affected flexural and compressive strength after 2 and 28 days, but only for pastes with $0.5 \%$ and $1.0 \%$ of nano-silica. In contrast, the use of nano-silica in larger amounts of $2 \%$ was limited due to its ability to agglomerate, which resulted in deterioration of the rheological and mechanical properties.

Calorimetric tests have shown that incorporation of nano-silica in the amount of $0.5 \%$ increased hydration heat and accelerated cement hydration. In the pre-induction period, which was associated with water adsorption and surface dissolution of cement grains, decrease in the rate of heat generation for the system with $0,5 \%$ of silica was observed, while for the postinduction period, an increase in the rate of heat release was noticed. As the amount of nanosilica increased, water requirement increased as well, while bonding and strength decreased. On the other hand, adding $0.5 \%$ of nano-silica strengthened the grip of the paste up to $37 \%$ after 24 hours of hardening and increased the early mortar strength to $23 \%$ and standard one to $10 \%$

\section{References}

[1] Czarnecki, L., Nanotechnologia w budownictwie. Przeglad budowlany, 2011, no 1, p.40-53.

[2] Sobolev, K., Ferrara, M. How nanotechnology can change the concrete word-Part 1. American Ceramic Bulletin, vol. 84, 2005, no10, p. 15-17.

[3] Sobolev,K., Ferrara, M. How nanotechnology can change the concrete word-Part 2. American Ceramic Bulletin, vol. 84, 2005, no 11, p. 16-20.

[4] Łukowski, P. Modyfikacja materiatowa betonu. Kraków: Polski cement, Stowarzyszenie Producentów Cementu, 2016.

[5] Kamal, M., Safan, M., Eltabey, M., Zaki El. S., Abu El-hassan. Compressive strength of Portland cement pastes and mortars containing $\mathrm{Cu}-\mathrm{Zn}$ nano-ferrite. International Journal of Nano Dimension, vol. 3, 2012, p. 91-100. 
[6] Li, H., Xiao, H., Yuan, J. and Ou, J. Microstructure of cement mortar with nano-particles. Composite Building Engineering, vol. 35, 2004, p. 185-159.

[7] Yu, R., Spiesz, P., Brouwers, H. Effect of nano-silica on the hydration and microstructure development of Ultra-High Performance Concrete (UHPC) with a low binder amount. Construction and Building Materials, vol. 65, 2014, p. 140-150.

[8] Senff, L., Hotza, D., Lucas, S., Ferreira, V., Labrincha, J. Effect of nano-SiO $\mathrm{S}_{2}$ and nano-TiO addition on the rheological behavior and the hardened properties of cement mortars. Material Science and Engineering, vol. 532, 2012, p. 354-361.

[9] Anyszka, R., Bieliński, D., Dobrowolski, O. Wpływ modyfikacji powierzchni napełniaczy mineralnych na właściwości kompozytów silikonowych. Inżynieria Materiałowa, 2011, no 4, p.301305.

[10] Raki, L., Beaudoin, J., Alizadeh, R., Makar, J., Sato T. Cement and Concrete Nanoscience and Nanotechnology. Materials 2010, no 3, p. 918-942.

[11] Kotsay, G. Effect of synthetic nanodispersed silica on the properties of Portland cement based mortars. Chemistry \& Chemical Technology, Vol. 7, No. 3, 2013, p. 335-338.

[12] PN-EN 196-3:2016-12: Cement testing methods - Part 3: Determination of bonding times and volume constant.

[13] EN 196-1:2016-07 Cement testing methods - Part 1: Determination of strength. 